\title{
REVIEW \\ Comparison of the Pattern of Crop Domestication between Two Asian Beans, Azuki Bean (Vigna angularis) and Rice Bean ( $V$. umbellata)
}

\author{
Takehisa ISEMURA, Norihiko TOMOOKA*, Akito KAGA and \\ Duncan A. VAUGHAN
}

Genebank, Division of Genome and Biodiversity Research, National Institute of Agrobiological Science (Tsukuba, Ibaraki 305-8602, Japan)

\begin{abstract}
Azuki bean (Vigna angularis) and rice bean ( V. umbellata) are locally important legumes that were domesticated in Asia. They are genetically closely related and therefore suitable for comparative genomics studies. The center of genetic diversity of azuki bean is in East Asia and it was most probably domesticated in Japan based on the archaeobotanical and genetic evidences. The center of genetic diversity and domestication of rice bean is in Southeast Asia. The domestication of rice bean involved fewer gene (QTLs) mutations with larger genetic effects than azuki bean. The distribution of major domestication genes in rice bean is limited to two linkage groups compared with five in azuki bean. In azuki bean the major domestication genes are abundantly detected on linkage group 9 (LG9), while in rice bean they were found on LG4. Surprisingly, many species specific QTLs were detected such as azuki bean's erect stem QTL on LG9 and rice bean's seed size increase QTL on LG4. Such species specific QTLs suggest the possibility that rice bean and azuki bean can provide novel genes for breeding. Comparative genomics among closely related species is an efficient way to find novel genes for breeding.
\end{abstract}

Discipline: Plant breeding

Additional key words: Asian Vigna, comparative genomics, QTL analysis

\section{Introduction}

After cereals, legumes are the most important group of plants to humans and account for $27 \%$ of global crop production $^{5}$. Most domesticated legumes belong to two distinct phylogenetic clades, Galegoid and Phaseoloid ${ }^{25}$. In the tribe Phaseoleae within the Phaseoloid clade, a large group of closely related domesticated species is present in the genera Phaseolus and Vigna. In addition, the Phaseoleae includes the most economically important domesticated legume, soybean (Glycine max).

The Vigna that were domesticated in Asia includes four important legume crops, azuki bean (Vigna angularis), mungbean ( $V$. radiata), black gram ( $V$. mungo), and rice bean $(V$. umbellata). Numerous differences in morphological and physiological traits associated with domestication are observed between cultivated and wild forms in these species. These four species are closely related in the same subgenus, Ceratotropis, and provide ideal materials for the comparative analyses of domestication genomics. The information from these comparative genomics analyses will promote the elucidation of species-differentiation within Ceratotropis, and the isolation of useful, specific genes for use in breeding. Therefore our research currently focuses on conducting the comparative genomics studies on the domestication among azuki bean, rice bean, mungbean, and black gram.

In this review, we present the latest information on the process of crop evolution based on the comparison of the QTL (quantitative traits loci) regions associated with the domestication of azuki bean and rice bean.

\section{Center of domestication and genetic diversity of azuki bean and rice bean}

Azuki bean and rice bean are phylogenetically closely related, have similar seed color variations (Figs. 1 and 2) 


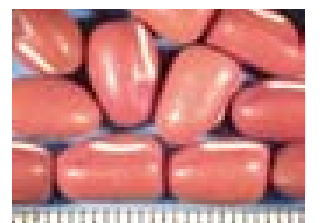

a: JP67672 (Japan)

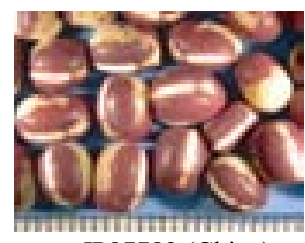

e: JP87782 (China)

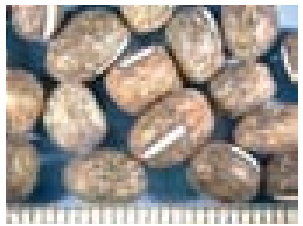

b: JP53709 (Japan)

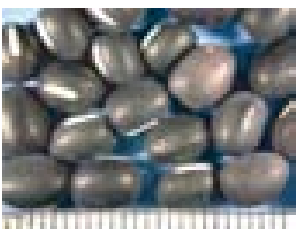

f: JP53592 (Japan)

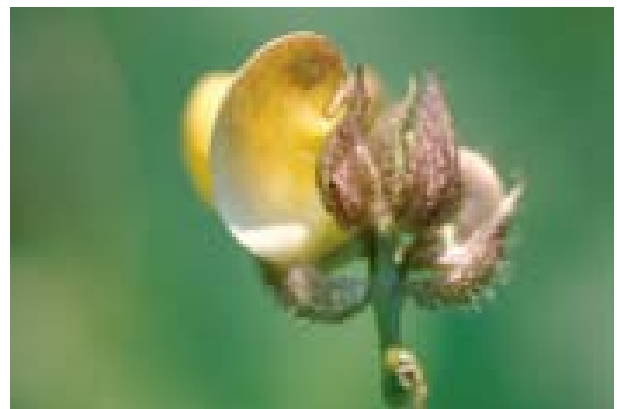

i: flowers

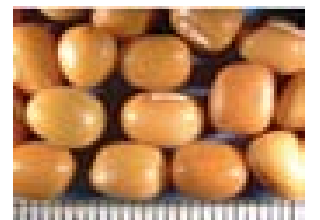

c: JP227106 (China)

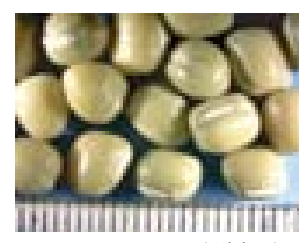

g: JP227029 (China)

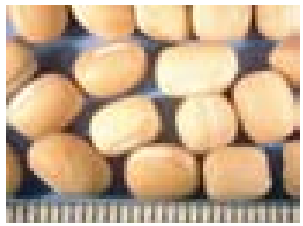

d: JP31179 (Japan)

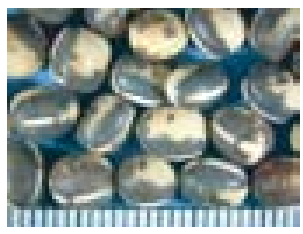

h: JP81185 (Korea)

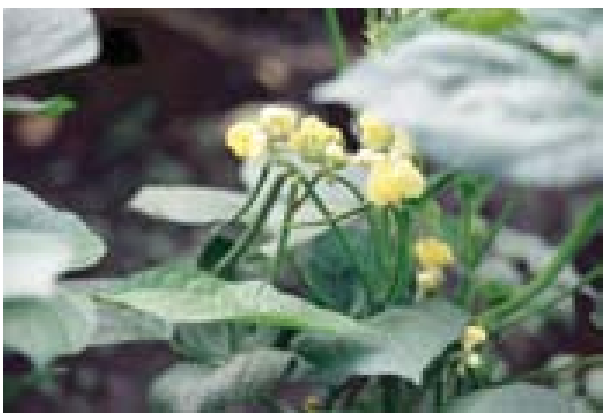

$\mathrm{j}:$ pods

Fig. 1. Pictures of seeds, flowers and pods in azuki bean (Vigna angularis) (after Tomooka ${ }^{24}$ )

a-h: Diversity of seed coat color and seed size, i: flowers and j: pods. JP No. is the accession identifier used in the NIAS gene bank, Japan. Country of origin is indicated in the parenthesis.

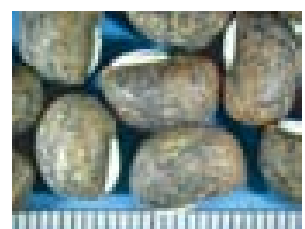

a: JP212059 (Myanmar)

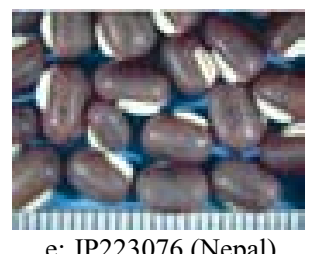

e: JP223076 (Nepal)

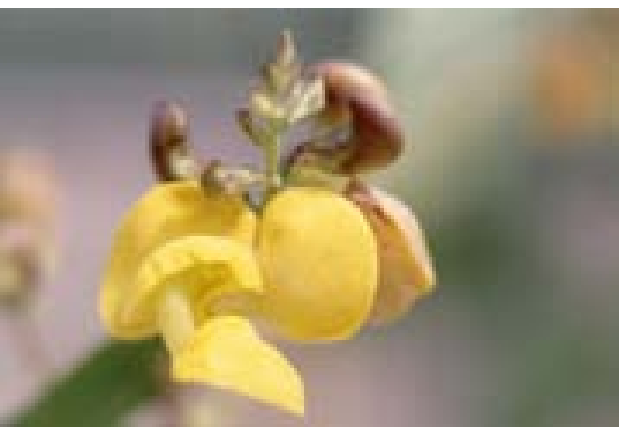

i: flowers

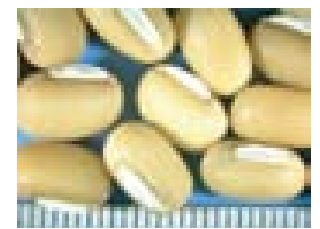

b: JP212062 (Myanmar)

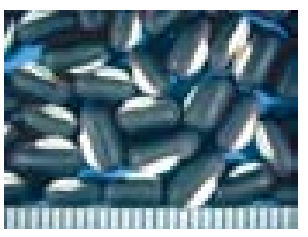

f: JP223064 (Nepal)

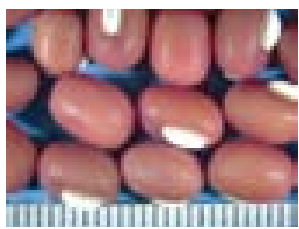

c: JP225374 (India)

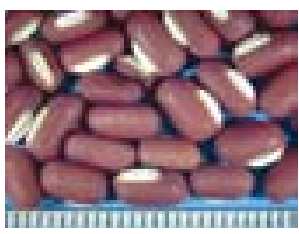

g: JP227454 (China)

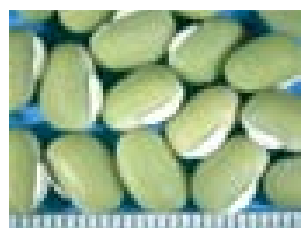

d: JP225373 (India)

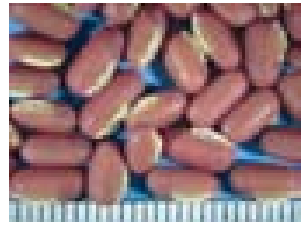

h: JP53836 (Japan)

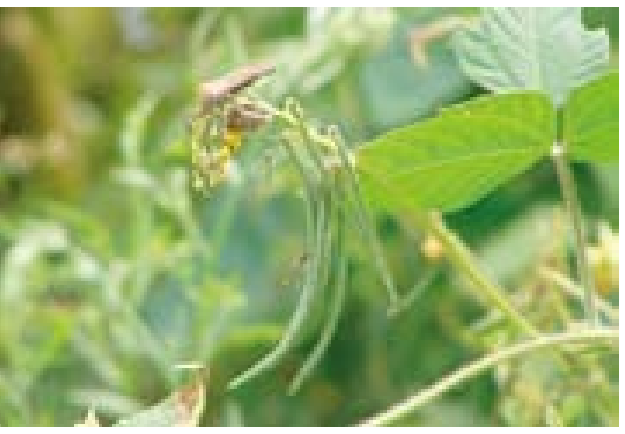

$\mathrm{j}$ : pods

Fig. 2. Pictures of seeds, flowers and pods in rice bean (Vigna umbellata) (after Tomooka ${ }^{24}$ )

a-h: Diversity of seed coat color and seed size, i: flowers and j: pods. JP No. is the accession identifier used in the NIAS gene bank, Japan. Country of origin is indicated in the parenthesis. 
and can produce fertile hybrid progenies when crossed ${ }^{21}$. Azuki bean is a traditional crop grown across East Asia to the southern fringe of the Himalaya ${ }^{21,27}$. The presumed wild ancestor of cultivated azuki bean is $V$. angularis var. nippo$n e n s i{ }^{22}$. This wild species is distributed across a wide area that corresponds with the broadleaved evergreen forest (the laurel forest) that spreads from Japan, the Korean Peninsula and China including Taiwan, to Nepal and Bhutan ${ }^{21,24}$ (Figs. 3 and 4). The broadleaved evergreen forest zone in Asia is characterized by a warm temperate climate with neither a prominent dry season nor a cold winter season. Hence the dominant species in this ecosystem are evergreen trees such as oak (Quercus spp.) and chestnut (Castanopsis spp.). In the broadleaved evergreen forest zone, the ethnic groups exhibit several common cultural components, such as tea consumption, the use of glutinous crops and fermented soybean products, and belief in the mysterious powers of the azuki bean. This cultural complex is called the broadleaved evergreen forest culture (the laurel forest culture). Based on an evaluation of the genetic diversity among 616 azuki bean accessions from a wide region by SSR analysis, the East Asian area (Japan, China and Korea) is considered to be the center of genetic diversity of azuki bean, and among East Asian countries, the highest genetic diversity is found in
Japanese accessions ${ }^{27}$. In addition, carbonized azuki bean seeds have been found from several archaeological sites in Japan such as the Awazu site in Shiga Prefecture (6000 BP) and the Torihama site in Fukui Prefecture (5000-6000 BP) ${ }^{23}$, predating archaeological remains of azuki bean in China and

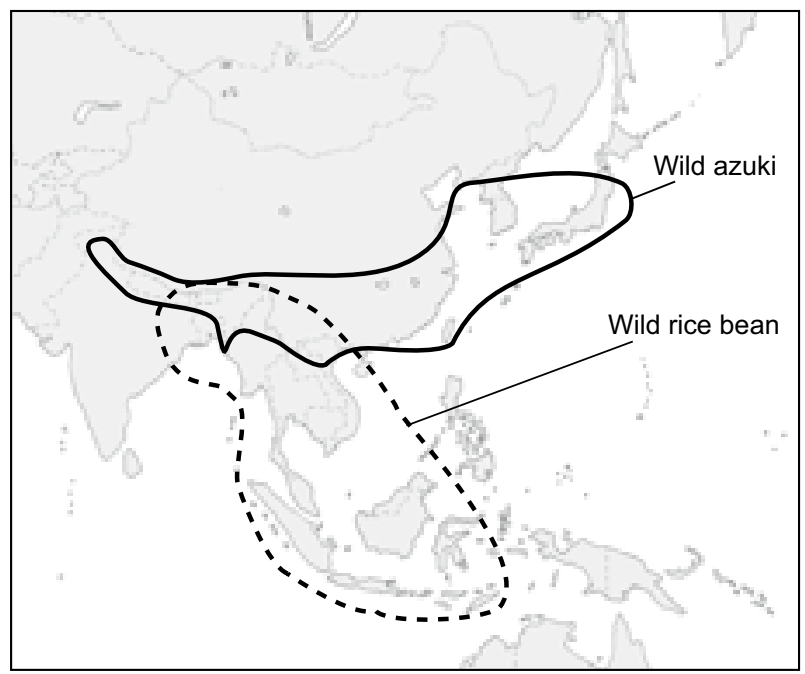

Fig. 3. Natural distribution of wild azuki bean and wild rice bean (revised from Tomooka ${ }^{24}$ )

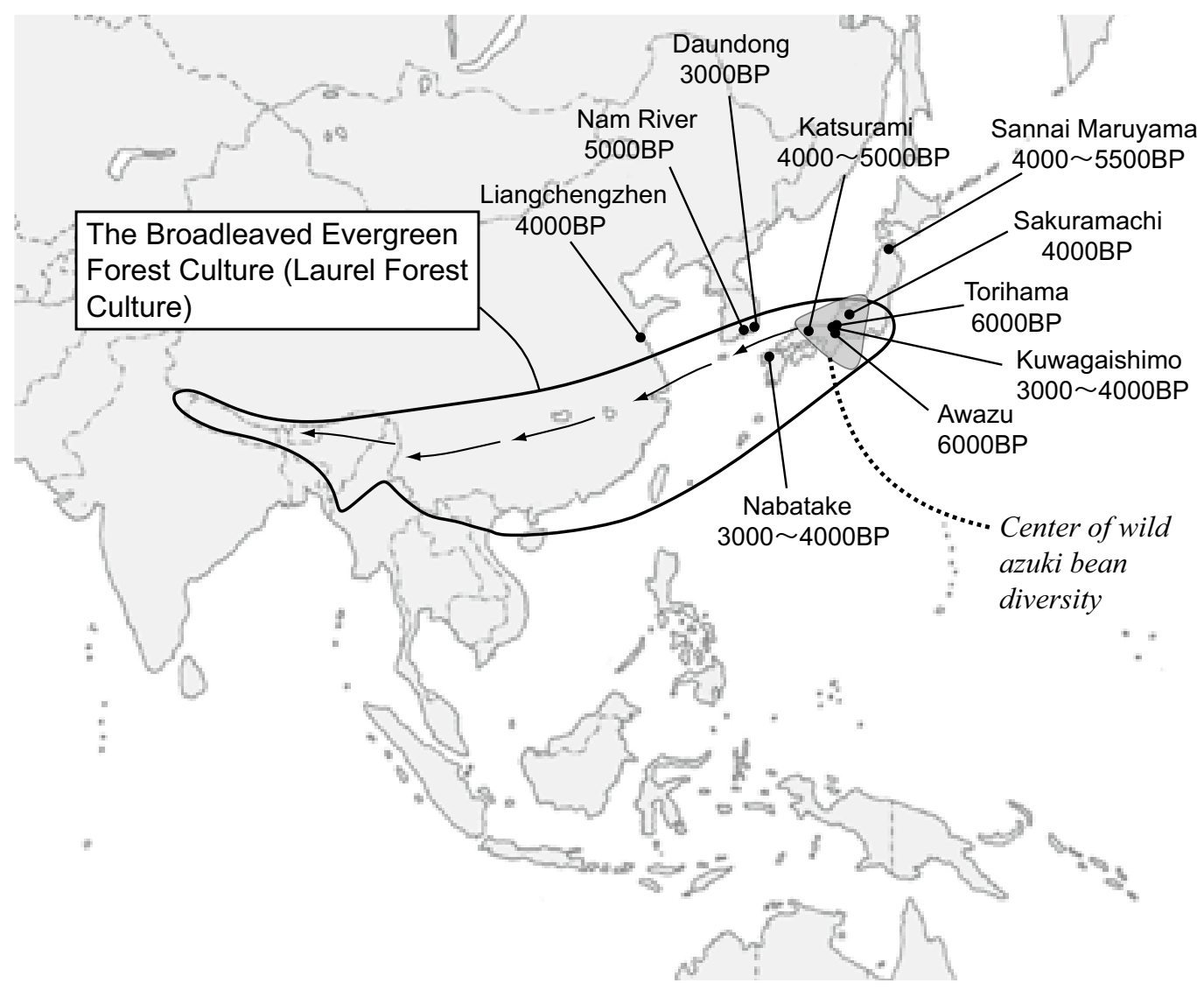

Fig. 4. Distribution of the "Broadleaved Evergreen Forest Culture (Laurel Forest Culture)", center of wild azuki bean diversity and sites of the archaeological remains where putative azuki bean seeds were found (revised from Tomooka $^{24}$ ) 
Korea $^{1}$ (Fig. 4). Based on these facts, Japan is considered to be a most probable place where azuki bean was domesticated $^{24}$.

Rice bean is a traditional crop grown across South, Southeast and East Asia ${ }^{20,21}$. Recently, this crop has been payed much attention for possessing a great potential to improve the lives of local farmers ${ }^{3,11}$. The wild form is distributed across a wide area of tropical monsoon forest from Nepal, Myanmar, Thailand, Laos, and southern China to East Timor $^{21,22}$ (Fig. 3). The largest variation in seed coat color and seed size is observed in the domesticated accessions from Southeast $\mathrm{Asia}^{24}$. In addition, based on AFLP ${ }^{20}$ and SSR analyses (Tian et al. unpublished data), the maximum genetic diversity of this crop is found in Southeast Asia. Based on these facts, Southeast Asia is considered to be the center of origin and genetic diversity of rice bean.

\section{Comparison of QTL regions associated with domestication between azuki bean and rice bean}

QTL (Quantitative Traits Loci) mapping technologies using molecular markers enable us to detect gene(s) location on the genome of quantitatively inherited traits, such as domestication related traits. The QTLs for the domestication related traits in azuki bean were identified in three populations derived from two cross combinations ${ }^{7,10}$. In this review, the QTL regions that were identified in the $\mathrm{BC}_{1} \mathrm{~F}_{1}$ population ${ }^{7}$ were compared with those in rice bean, since the QTL regions were identified in the $\mathrm{BC}_{1} \mathrm{~F}_{1}$ population in rice bean ${ }^{8}$. Almost all common molecular markers showed a high level of co-linearity within the same linkage group. This revealed these two species had a highly conserved genomic structure which enabled accurate comparison of QTLs.

\section{Difference in number of QTLs and linkage groups associated with domestication}

Twenty-eight domestication traits were compared between azuki bean and rice bean. For 28 traits, a total of 76 QTLs were found in azuki bean ${ }^{7}$, whereas 69 QTLs were found in rice bean ${ }^{8}$. In azuki bean, the QTLs with large effect $(\mathrm{PEV}>20 \%)$ were found on five linkage groups (LG1: seed dormancy and internode length, LG2: seed size and epicotyl and lower internode length, LG7: pod dehiscence and pod size, LG8: pod size, and LG9: twining habit) (Fig. 5). On the other hand, the heritability pattern for domestication related traits was simpler in rice bean, and most of QTLs are distributed in clusters on a limited number of linkage groups. In addition, the number of QTLs with large effect were fewer and the distribution of these QTLs was limited to two linkage groups (LG4: seed and pod size and seed dormancy, and LG7: pod dehiscence) (Fig. 5).
This indicates that the mutations that cause changes related to domestication have occurred on fewer linkage groups in rice bean.

\section{Difference in distribution region of QTLs associated with domestication}

Among QTLs detected in azuki bean (76) and rice bean (69), only 15 QTLs were considered as common between azuki bean and rice bean (Table 1, Fig. 5). Furthermore, nine of the 15 common QTLs were observed for seed size related traits (100-seed weight, seed length, seed width, and seed thickness). The QTLs for seed related traits on LG1, LG2 and LG7 were common between the two species. In particular the QTLs on LG2 had the largest effect in azuki bean and had the second largest effect in rice bean. One common QTL for pod dehiscence was found on LG7 in the two species. These results show similar mutations for seed size and pod dehiscence, and have been found and used by farmers during the independent domestication processes of these two legumes.

Domestication genes related to dormancy and pod size differed between azuki bean and rice bean. For example, the seed dormancy related QTL with the largest effect was detected on LG1 and LG4 in azuki bean and rice bean, respectively. No common QTL for seed dormancy was found between these two species. Similarly pod size related QTL with the largest effect was detected on LG7 and LG4 in azuki bean and rice bean, respectively, and no common QTL was found.

A remarkable difference was observed for the pattern of distribution of the main QTLs between azuki bean and rice bean. Especially, differences were found on the linkage groups 4 and 9. Many QTLs with large effect were detected on LG9 of azuki bean, whereas few QTLs were detected on linkage group 9 of rice bean. In contrast, major QTLs for domestication related traits were abundantly detected on linkage group 4 in rice bean, whereas only a few QTLs were detected on LG4 of azuki bean. Such differences suggest the possibility that rice bean and azuki bean harbor specific useful genes and can play important roles as new genes resources for each other. The twining related QTL with large effect on LG9 was specific to azuki bean, whereas the seed size related QTL with large effect on LG4 was specific to rice bean. The hybrids can be produced between azuki bean and rice bean when rice bean is used as the seed parent ${ }^{9}$. Therefore, it seems that the seed weight QTL on LG4 in rice bean and the QTL for the loss of twining habit on LG 9 in azuki bean are particularly useful for the breeding of larger seeded azuki bean varieties and determinate rice bean varieties, respectively. 


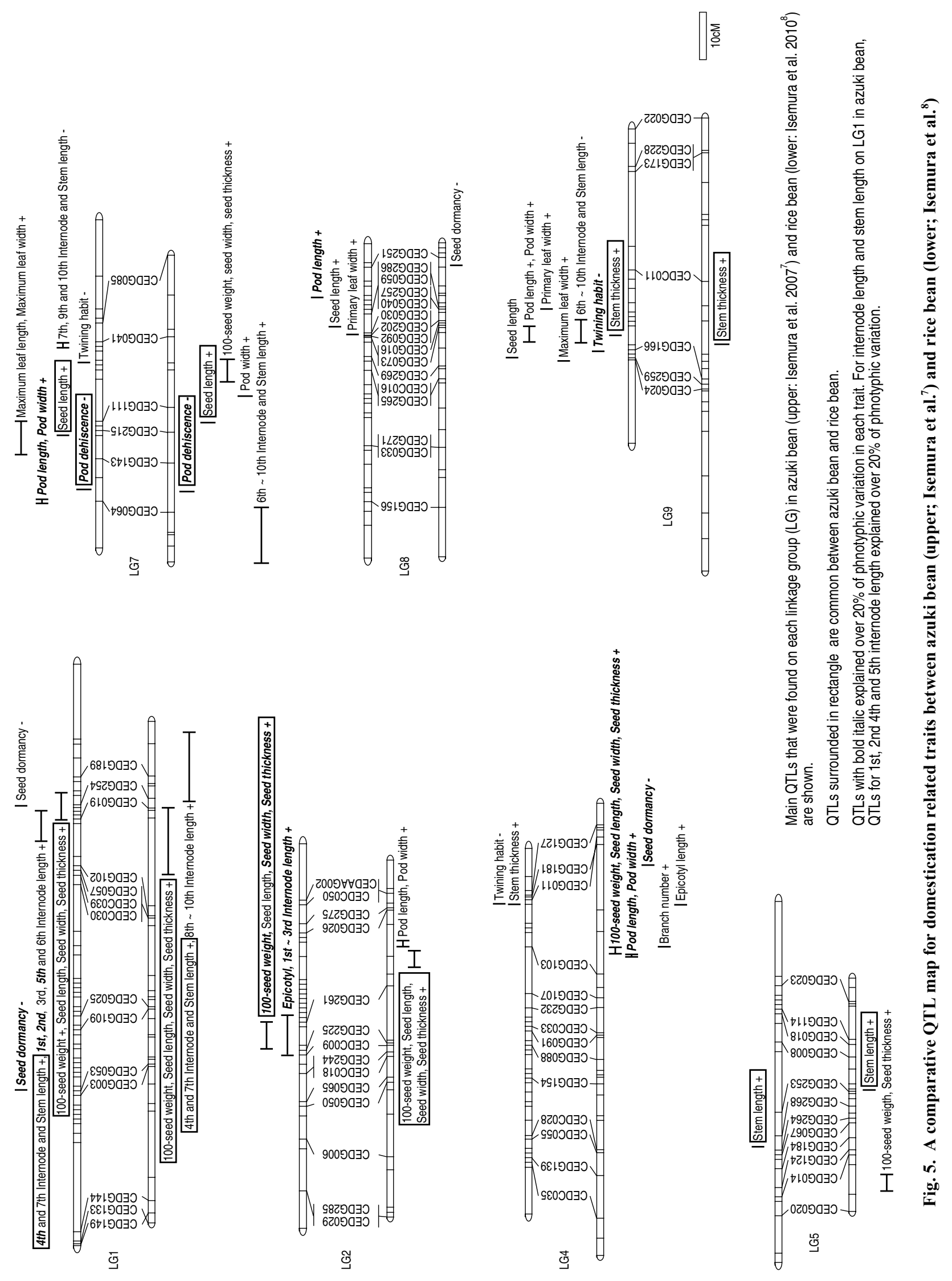


Table 1. The common QTL detected between rice bean and azuki bean

\begin{tabular}{|c|c|c|c|c|c|c|}
\hline \multirow[t]{2}{*}{ Trait } & \multicolumn{3}{|c|}{ Azuki bean ${ }^{1)}$} & \multicolumn{3}{|c|}{ Rice bean ${ }^{2)}$} \\
\hline & QTL & LG & Nearest marker & QTL & LG & Nearest marker \\
\hline \multirow[t]{2}{*}{ 100-seed weight } & Sd100wt1.1.2+ & 1 & CEDG090 & Sd100wt4.1.1+ & 1 & CEDG019 \\
\hline & Sd100wt1.2.1+ & 2 & CEDG261 & Sd100wt4.2.1+ & 2 & сp08299 \\
\hline \multirow[t]{3}{*}{ Seed length } & Sdl1.1.2+ & 1 & CEDG090 & Sdl4.1.1+ & 1 & BM181 \\
\hline & Sdl1.2.1+ & 2 & CEDG261 & Sdl4.2.1+ & 2 & сp08299 \\
\hline & Sdl1.7.1+ & 7 & CEDG111 & Sdl4.7.1+ & 7 & CEDG111 \\
\hline \multirow[t]{2}{*}{ Seed width } & $S d w 1.1 .1+$ & 1 & CEDG090 & $S d w 4.1 .1+$ & 1 & cp05137 \\
\hline & $S d w 1.2 .1+$ & 2 & CEDC009 & $S d w 4.2 .1+$ & 2 & cp08299 \\
\hline \multirow[t]{2}{*}{ Seed thickness } & Sdt1.1.1+ & 1 & CEDG090 & $S d t 4.1 .1+$ & 1 & CEDG019 \\
\hline & Sdt1.2.1+ & 2 & CEDC009 & $S d t 4.2 .1+$ & 2 & сp08299 \\
\hline Pod dehiscence & Pdt1.7.1- & 7 & CEDG064 & Pdt4.7.1- & 7 & CEDG064 \\
\hline 4th internode length & St4i1.1.1+ & 1 & CEDG090 & St4i4.1.1+ & 1 & CEDG254 \\
\hline 7th internode length & St7il.1.1+ & 1 & CEDG090 & St7i4.1.1+ & 1 & CEDG283 \\
\hline \multirow[t]{2}{*}{ Stem length } & Stll.1.1+ & 1 & CEDG090 & Stl4.1.1+ & 1 & CEDG189 \\
\hline & Stl1.5.1+ & 5 & CEDG067 & Stl4.5.1+ & 5 & CEDG027 \\
\hline Stem thickness & Stt1.9.1+ & 9 & CEDG238 & Stt4.9.1+ & 9 & GATS11 \\
\hline
\end{tabular}

1): After Isemura et al. ${ }^{7} 2007$.

2): After Isemura et al. ${ }^{8} 2010$.

Table 2. QTLs for domestication related traits in legumes within the tribe Phaseoleae

\begin{tabular}{|c|c|c|c|c|c|}
\hline Crop & Cross combination ${ }^{1)}$ & Population & Trait & $\begin{array}{l}\text { No. of } \\
\text { QTLs }\end{array}$ & Reference \\
\hline azuki bean & $\begin{array}{l}\text { Vigna nepalensis (JP107881) } \\
\text { V. angularis var. angularis(JP81481) } \\
\text { V. angularis var. angularis(JP81481) }\end{array}$ & $\begin{array}{l}\mathrm{BC}_{1} \mathrm{~F}_{1} \\
\text { or } \\
\mathrm{BC}_{1} \mathrm{~F}_{1: 2}\end{array}$ & $\begin{array}{l}\text { seed dormancy } \\
\text { pod dehiscence } \\
100 \text {-seed weight } \\
\text { pod length } \\
\text { stem thickness } \\
\text { stem length } \\
\text { twining habit }\end{array}$ & $\begin{array}{l}5 \\
1 \\
2 \\
4 \\
3 \\
5 \\
3\end{array}$ & Isemura et al. 2007 \\
\hline azuki bean & $\begin{array}{l}\text { Vigna nepalensis (JP107881) } \\
\text { V. angularis var. angularis(JP81481) }\end{array}$ & $\begin{array}{c}\mathrm{F}_{2} \\
\text { or } \\
\mathrm{F}_{2: 3}\end{array}$ & $\begin{array}{l}\text { seed dormancy } \\
\text { pod dehiscence } \\
100 \text {-seed weight } \\
\text { pod length } \\
\text { stem thickness } \\
\text { stem length } \\
\text { twining habit } \\
\text { flowering time }\end{array}$ & $\begin{array}{l}1 \\
1 \\
6 \\
3 \\
1 \\
4 \\
1 \\
1\end{array}$ & Isemura et al. ${ }^{7} 2007$ \\
\hline azuki bean & $\begin{array}{l}\text { Vigna angularis var. angularis (JP109685) } \\
\text { V. angularis var. nipponensis (JP110658) }\end{array}$ & $\begin{array}{c}\mathrm{F}_{2} \\
\text { or } \\
\mathrm{F}_{2: 3}\end{array}$ & $\begin{array}{l}\text { seed dormancy } \\
\text { pod dehiscence } \\
100 \text {-seed weight } \\
\text { pod length } \\
\text { stem thickness } \\
\text { stem length } \\
\text { twining habit } \\
\text { flowering time } \\
\text { pod maturity }\end{array}$ & $\begin{array}{l}2 \\
1 \\
7 \\
7 \\
4 \\
2 \\
1 \\
5 \\
5\end{array}$ & Kaga et al. ${ }^{10} 2008$ \\
\hline rice bean & $\begin{array}{l}\text { Vigna umbellata (wild: JP210639) } \\
\text { V. umbellata (cultivated: JP217439) } \\
\text { V. umbellata (cultivated: JP217439) }\end{array}$ & $\begin{array}{c}\mathrm{BC}_{1} \mathrm{~F}_{1} \\
\text { or } \\
\mathrm{BC}_{1} \mathrm{~F}_{1: 2}\end{array}$ & $\begin{array}{l}\text { seed dormancy } \\
\text { pod dehiscence } \\
100 \text {-seed weight } \\
\text { pod length } \\
\text { stem thickness } \\
\text { stem length } \\
\text { pod maturity }\end{array}$ & $\begin{array}{l}5 \\
1 \\
7 \\
3 \\
1 \\
3 \\
1\end{array}$ & Isemura et al. ${ }^{8} 2010$ \\
\hline
\end{tabular}


Table 2. Continued.

\begin{tabular}{|c|c|c|c|c|c|}
\hline Crop & Cross combination ${ }^{1)}$ & Population & Trait & $\begin{array}{l}\text { No. of } \\
\text { QTLs }\end{array}$ & Reference \\
\hline mungbean & $\begin{array}{l}\text { Vigna radiata var. radiata (VC3890) } \\
\text { V. radiata var. sublobata (TC1966) }\end{array}$ & $\mathrm{F}_{2}$ & 100 -seed weight & 4 & Fatokun et al. $^{2} 1992$ \\
\hline mungbean & $\begin{array}{l}\text { Vigna radiata var. radiata } \text { (Berken) } \\
\text { V. radiata var. sublobata (ACC41) }\end{array}$ & RIL & $\begin{array}{l}\text { 100-seed weight (field) } \\
100 \text {-seed weight (glasshouse) } \\
\text { seed dormancy (field) } \\
\text { seed dormancy (glasshouse) }\end{array}$ & $\begin{array}{l}8 \\
9 \\
4 \\
1\end{array}$ & Humphry et al. ${ }^{6} 2005$ \\
\hline cowpea & $\begin{array}{l}\text { Vigna unguiculata var.unguiculata (IT2246-4) } \\
\text { V. unguiculata var. dekindtiana (TVNI963) }\end{array}$ & $\mathrm{F}_{2}$ & 100 - seed weight & 2 & Fatokun et al. $^{2} 1992$ \\
\hline common bean & $\begin{array}{l}\text { Phaseolus vulgaris (cultivated: Midas) } \\
\text { P. vulgaris (wild: G12873) }\end{array}$ & RIL & $\begin{array}{l}\text { seed dormancy } \\
\text { pod dehiscence } \\
100 \text {-seed weight } \\
\text { pod length } \\
\text { determinacy } \\
\text { twining habit } \\
\text { number of nodes } \\
\text { flowering time }\end{array}$ & $\begin{array}{l}4 \\
1 \\
4 \\
3 \\
1 \\
1 \\
3 \\
3\end{array}$ & Koinange et al. ${ }^{14} 1996$ \\
\hline soybean & $\begin{array}{l}\text { Glycyne max }(\text { Tokei } 780) \\
\text { G. soja }(\text { Hidaka4) }\end{array}$ & RIL & $\begin{array}{l}\text { seed dormancy } \\
\text { pod dehiscence } \\
100 \text {-seed weight } \\
\text { stem length (plant height) } \\
\text { determinacy } \\
\text { twining habit } \\
\text { number of nodes } \\
\text { flowering time }\end{array}$ & $\begin{array}{l}2 \\
2 \\
3 \\
2 \\
1 \\
3 \\
2 \\
2\end{array}$ & Liu et al. ${ }^{15} 2007$ \\
\hline soybean & $\begin{array}{l}\text { Glycyne max }(\mathrm{A} 81-356022) \\
\text { G. soja }(\mathrm{PI} 468916)\end{array}$ & $\mathrm{F}_{2: 4}$ & seed dormancy & 4 & Keim et al. ${ }^{12} 1990 \mathrm{a}$ \\
\hline soybean & $\begin{array}{l}\text { Glycyne max }(\text { Tokei } 780) \\
\text { G. soja (Hidaka4) }\end{array}$ & $\mathrm{F}_{2}$ & seed dormancy & 3 & Sakamoto et al..$^{19} 2004$ \\
\hline soybean & $\begin{array}{l}\text { Glycyne max }(\mathrm{V} 71-370) \\
\text { G. soja }(\mathrm{PI} 407.162)\end{array}$ & $\mathrm{F}_{2}$ & 100 -seed weight & 6 & Maughan et al. ${ }^{16} 1996$ \\
\hline soybean & $\begin{array}{l}\text { Glycyne max (A81-356022) } \\
\text { G. soja (PI468916) }\end{array}$ & $\mathrm{F}_{2}$ & $\begin{array}{l}\text { stem length } \\
\text { stem thickness (stem diameter) } \\
\text { flowering time } \\
\text { pod maturity }\end{array}$ & $\begin{array}{l}1 \\
1 \\
1 \\
3\end{array}$ & Keim et al. ${ }^{13} 1990 \mathrm{~b}$ \\
\hline
\end{tabular}

1): First line, second line and third line $\left(\mathrm{BC}_{1} \mathrm{~F}_{1}\right.$ population) shows female parent, male parent and recurrent parent, respectively.

\section{Comparison of QTLs for domestication within tribe Phaseoleae}

The domestication related QTLs that have been identified for the legumes within the tribe Phaseoleae are summarized in Table 2. Many domestication related traits for different organs have been analyzed in azuki bean ${ }^{7,10}$, rice bean $^{8}$, mungbean ${ }^{2,6}$ (Isemura et al. in preparation), cowpea ${ }^{2}$, common bean ${ }^{14}$ and soybean ${ }^{12,13,15,16,19}$. These studies have revealed that domestication related traits are always controlled by a few major genes plus some minor genes. In addition, these genes are distributed in the clusters on limited genomic regions on a small number of linkage groups. These genes are the basis for the "domestication syn- drome" ${ }^{4}$. The same situation is also found in the Graminaceous crops such as rice ${ }^{26}$, maize ${ }^{17}$ and pearl mil$\operatorname{let}^{18}$.

Fatokun et al. ${ }^{2}$ (1992) showed that a common 100-seed weight QTL with the largest effect was found in the conserved genomic region between cowpea (linkage group ii) and mungbean (linkage group ii). Our results showed that azuki bean ${ }^{7,10}$ and rice bean ${ }^{8}$ also contained this conserved genomic region on LG1 and that the QTL for seed weight was again found in this region in both species. This seed size related gene contributed to domestication in 4 different Vigna crops. Similarly, a common QTL for seed weight was found in the conserved genomic region of cowpea ${ }^{2}$ (linkage group vi), mungbean ${ }^{5}$ (linkage group B) and soy- 
bean $^{16}$ (linkage group M).

Although many domestication QTLs have been detected for azuki bean ${ }^{7,10}$, rice bean ${ }^{8}$, common bean ${ }^{14}$, and soybean ${ }^{15}$, comparison is not possible for most of the QTLs at present due to lack of common markers. We are now trying to accumulate novel molecular markers that can be commonly applied among different legume species within Phaseoleae.

\section{Acknowledgments}

This study was funded by a Grants-in Aid for Scientific Research (KAKENHI No. 18390009 and No. 21380202) of the Japanese Ministry of the Education, Culture, Sports, Science and Technology and by the Genebank project of the Ministry of Agriculture, Forestry and Fisheries of Japan. The authors would like to thank the following staff of the National Institute of Agrobiological Sciences for technical support: T. Yoshida, T. Nobori, H. Nakazawa, N. Karino, T. Nemoto, Y. Ito, S. Hirashima, E. Iizumi, M. Akiba, T. Omizu, T. Misawa, J. Inoue, K. Sugimoto, H. Uchiyama, T. Taguchi, and H. Tomiyama.

\section{References}

1. Crawford, G. W. (2005) East Asian plant domestication. In Archaeology of Asia, ed. Stark, M. T., Blackwell Publishing, Oxford, UK, 78-95.

2. Fatokun, C. A. et al. (1992) Evidence for orthologous seed weight genes in cowpea and mung bean based on RFLP mapping. Genetics, 132, 841-846.

3. FOSRIN (2010) Background information, About ricebean. Food security through ricebean research in India and Nepal. http://www.ricebean.org/about.htm.

4. Gepts, P. (2004) Crop domestication as a long-term selection experiment. Plant Breed. Rev., 24 (part 2), 1-44.

5. Graham, P. H. \& Vance, C. P. (2003) Legumes: importance and constraints to greater use. Plant Physiol., 131, 872-877.

6. Humphry, M. E. et al. (2005) Relationships between hardseededness and seed weight in mungbean (Vigna radiata) assessed by QTL analysis. Plant Breed., 124, 292-298.

7. Isemura, T. et al. (2007) Genome dissection of traits related to domestication in azuki bean (Vigna angularis) and their comparison with other warm season legumes. Ann. Bot., 100, 1053-1071.

8. Isemura, T. et al. (2010) The genetics of domestication of rice bean, Vigna umbellata. Ann. Bot. doi: 10.1093/aob/mcq188, www.aob.oxfordjournals.org.

9. Kaga, A. et al. (2000) Comparative molecular mapping in Ceratotropis species using an interspecific cross between azuki bean (Vigna angularis) and rice bean (V. umbellata). Theor. Appl. Gent., 100, 207-213.

10. Kaga, A. et al. (2008) The genetics of domestication of azuki bean (Vigna angularis). Genetics, 178, 1013-1036.

11. Kashiwaba, K. et al. (2003) Characterization of resistance to three bruchid species (Callosobruchus spp., Coleoptera, Bruchidae) in cultivated rice bean (Vigna umbellata). J. Econ. Entomol., 96, 207-213.

12. Keim, P., Diers, B. W. \& Shoemaker, R. C. (1990a) Genetic analysis of soybean hard seededness with molecular markers. Theor. Appl. Genet., 79, 465-469.

13. Keim, P. et al. (1990b) RFLP mapping in soybean: association between marker loci and variation in quantitative traits. Genetics, 126, 735-742.

14. Koinange, E. M. K., Singh, S. P. \& Gepts, P. (1996) Genetic control of the domestication syndrome in common bean. Crop Sci., 36, 1037-1045.

15. Liu, B. et al. (2007) QTL mapping of domestication-related traits in soybean (Glycine max). Ann. Bot., 100, 1027-1038.

16. Maughan, P. J., Maroof, M. A. S. \& Buss, G. R. (1996) Molecular-marker analysis of seed-weight: genomic locations, gene action, and evidence for orthologous evolution among three legume species. Theor. Appl. Genet., 93, 574579.

17. Paterson, A. H. et al. (1995) Convergent domestication of cereal crops by independent mutations at corresponding genetic loci. Science, 269, 1714-1717.

18. Poncet, V. et al. (2000) Genetic control of domestication traits in pearl millet (Pennisetum glaucum L., Poaceae). Theor. Appl. Genet., 100, 147-159.

19. Sakamoto, S. et al. (2004) Marker-assisted analysis for soybean hard seededness with isozyme and simple sequence repeat loci. Breed. Sci., 54, 133-139.

20. Seehalak, W. et al. (2006) Genetic diversity of the Vigna germplasm from Thailand and neighboring regions revealed by AFLP analysis. Genet. Resour. Crop Evol., 53, 10431059.

21. Tomooka, N. et al. (2002) The Asian Vigna: Genus Vigna subgenus Ceratotropis genetic resources. Kluwer Academic Publishers, Dordrecht., Netherlands, pp.270.

22. Tomooka, N. et al. (2006) Conservation of legume-rhizobia genetic diversity in East Timor, 2005. Annual Report on Exploration and Introduction of Plant Genetic Resources, 22, 135-147.

23. Tomooka, N. (2007) Archaeological remains of azuki bean (Vigna angularis). Goggle map. http://maps.google.co.jp/ $\mathrm{maps} / \mathrm{ms}$ ?hl $=$ ja\&ie $=$ UTF $8 \& \mathrm{msa}=0 \& \mathrm{msid}=10145821838145$ $8921300.000001124500 b f 8 f 41 \mathrm{~d} 2 \mathrm{~b} \& \mathrm{z}=5$ \&om $=1$.

24. Tomooka, N. (2009) The origins of rice bean (Vigna umbellata) and azuki bean ( $V$. angularis): The evolution of two lesser-known Asian beans. In An illustrated eco-history of the Mekong River Basin, ed. Akimichi, T., White Lotus Co. Ltd., Bangkok, Thailand, 33-35.

25. Wojciechowski, M. F., Lavin, M. \& Sanderson, M. J. (2004) A phylogeny of legumes (Leguminosae) based on analysis of the plastid MATK gene resolves many well-supported subclades within the family. Am. J. Bot., 91, 1846-1862.

26. Xiong, L. Z. et al. (1999) Identification of genetic factors controlling domestication-related traits of rice using $\mathrm{F}_{2}$ population of a cross between Oryza sativa and O. rufipogon. Theor. Appl. Genet., 98, 243-251.

27. Xu, H. X. et al. (2008) Genetic diversity of the azuki bean (Vigna angularis (Willd.) Ohwi \& Ohashi) gene pool as assessed by SSR markers. Genome, 51, 728-738. 